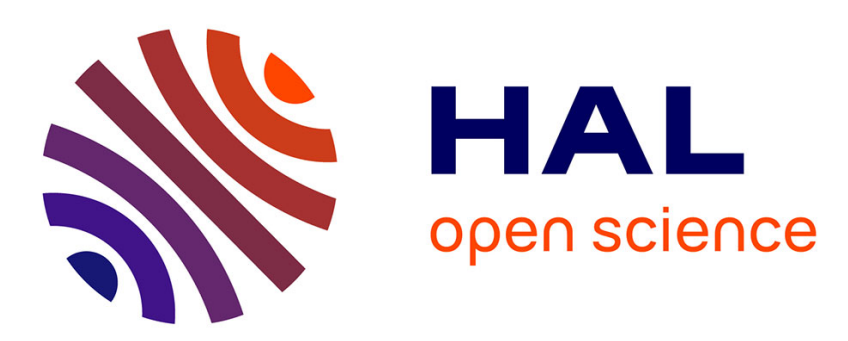

\title{
Effect of ultrasound on the induction time and the metastable zone widths of potassium sulphate
}

Nathalie Lyczko, Fabienne Espitalier, Olivier Louisnard, Jacques

Schwartzentruber

\section{- To cite this version:}

Nathalie Lyczko, Fabienne Espitalier, Olivier Louisnard, Jacques Schwartzentruber. Effect of ultrasound on the induction time and the metastable zone widths of potassium sulphate. Chemical Engineering Journal, 2002, 86 (3), pp.233-241. 10.1016/S1385-8947(01)00164-4 . hal-01678814

\section{HAL Id: hal-01678814 https://hal.science/hal-01678814}

Submitted on 10 Sep 2018

HAL is a multi-disciplinary open access archive for the deposit and dissemination of scientific research documents, whether they are published or not. The documents may come from teaching and research institutions in France or abroad, or from public or private research centers.
L'archive ouverte pluridisciplinaire $\mathbf{H A L}$, est destinée au dépôt et à la diffusion de documents scientifiques de niveau recherche, publiés ou non, émanant des établissements d'enseignement et de recherche français ou étrangers, des laboratoires publics ou privés. 


\title{
Effect of ultrasound on the induction time and the metastable zone widths of potassium sulphate
}

\author{
Nathalie Lyczko*, Fabienne Espitalier, Olivier Louisnard, Jacques Schwartzentruber \\ Ecole des Mines d'Albi-Carmaux, Allée des Sciences, 81013 Albi Cedex 09, France
}

\begin{abstract}
A study of cooling crystallisation of a potassium sulphate solution in a batch reactor is described in this paper. The effect of ultrasound on primary nucleation was investigated by measures of induction time and metastable zone width of unseeded solutions. The appearance of crystals is detected by conductivity measurements.

The experimental results show that ultrasound has an effect on the primary nucleation of potassium sulphate. Ultrasound allows induction time and metastable zone width to be significantly reduced.
\end{abstract}

Keywords: Induction time; Metastable zone; Ultrasound; Potassium sulphate; Nucleation

\section{Introduction}

Crystallisation is an important process used in many domains, such as chemical, pharmaceutical and petrochemical industries. Works on the influence of ultrasound in crystallisation/precipitation processes have been published for several years [1-3].

The aim of our study is to determine if ultrasound has an effect on primary nucleation. Ultrasound is used only as a tool to induce the nucleation. For this, we carried out experiments of cooling crystallisation. Potassium sulphate has been chosen as a model product because a lot of data is available in the literature, such as solubility, nucleation and growth kinetics [4-6]. This investigation was divided into two parts. First, the induction time has been measured both with and without ultrasound. In the second part, the metastable zone width has been determined at a constant cooling rate for potassium sulphate solutions saturated at $30{ }^{\circ} \mathrm{C}$.

\section{Theory}

The primary nucleation occurs in the absence of solid particles of the crystallised substance. For homogeneous primary nucleation, no solid phase is required, while the

\footnotetext{
* Corresponding author. Tel.: +33-5-63-49-32-26; fax: +33-5-63-49-30-25.

E-mail address: nathalie.lyczko@ifp.fr (N. Lyczko).
}

heterogeneous primary nucleation is catalytically initiated by any foreign surface, such as the reactor wall, the stirring rod or solid impurities.

The primary nucleation rate is defined as the number of nuclei generated per unit volume and per unit time. The homogeneous primary nucleation rate is generally expressed as the following classical relation $[7,8]$ :

$$
J_{\text {hom }}=K_{\text {hom }} \exp \left[-\frac{4}{27} \frac{\gamma_{\mathrm{s}}^{3} V_{\mathrm{m}}^{2} \beta^{3}}{\left(T k_{\mathrm{B}} v \alpha \ln S\right)^{2}}\right]
$$

For the heterogeneous primary nucleation we have

$$
J_{\text {het }}=K_{\text {het }} \exp \left[-\frac{4}{27} \frac{\gamma_{\mathrm{s}}^{3} V_{\mathrm{m}}^{2} \beta^{3}}{\left(T k_{\mathrm{B}} v \alpha \ln S\right)^{2}} f(\theta)\right]
$$

where $f(\theta)$ is a function of the angle of contact between the crystalline deposit and substrate

$$
f(\theta)=\frac{\left\lfloor(2+\cos \theta)(1-\cos \theta)^{2}\right\rfloor}{4} .
$$

\subsection{Induction period}

In order to characterise the primary nucleation, we can measure the induction period which is defined as the time elapsed between the creation of supersaturation and the appearance of crystals. Kashiev et al. proposed a general expression of induction time valid for all nuclei, which appear and grow in a saturated solution [9]:

$t_{\text {ind }}=\frac{N_{\mathrm{c}}}{J}+\left\lfloor\frac{\alpha_{0}}{a_{p} J G^{p-1}}\right\rfloor$ 


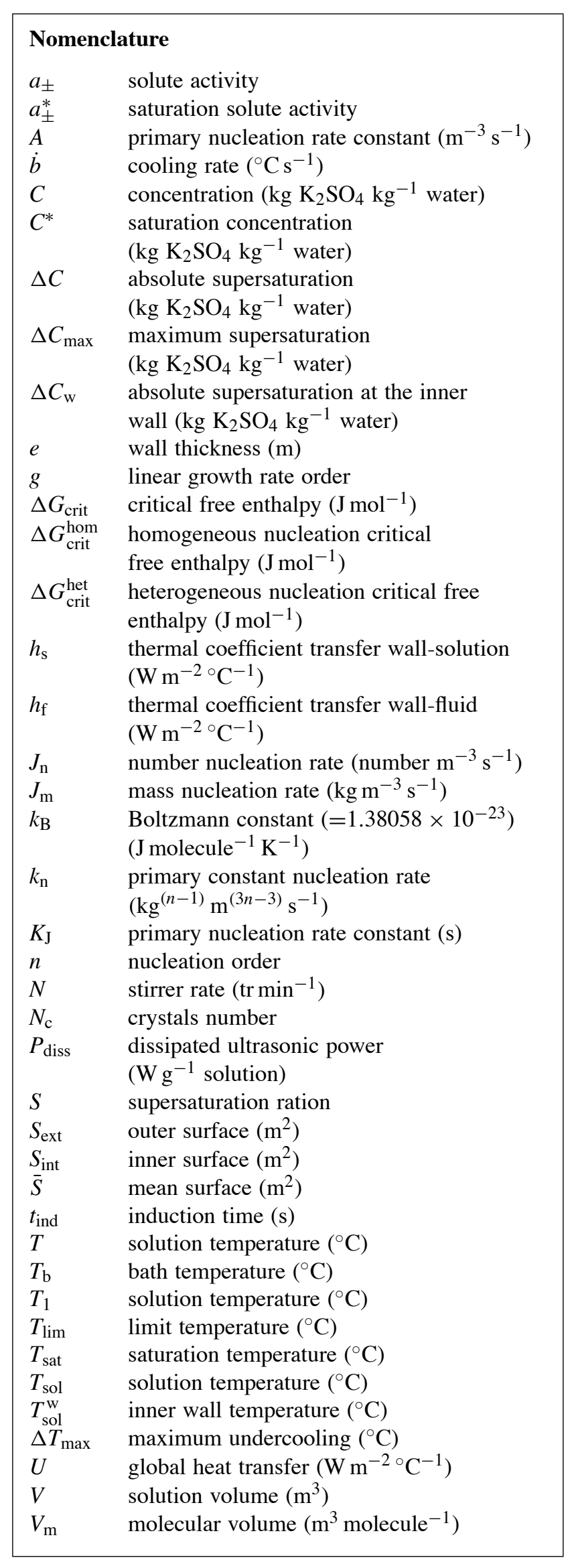

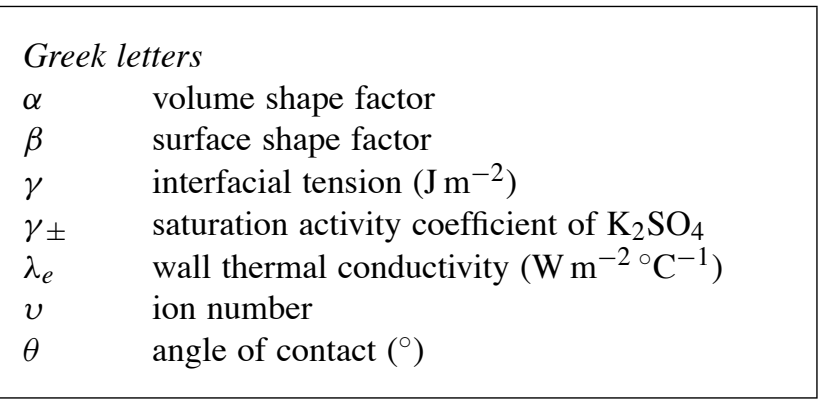

Assumptions can be made to simplify the expression of the induction time [8].

Three cases are possible:

1. $t_{\mathrm{n}}$ is much higher than $t_{\mathrm{g}}$. The nucleation is predominant.

2. $t_{\mathrm{n}}$ is of the same size order as $t_{\mathrm{g}}$. Nucleation and growth act upon the induction time.

3. $t_{\mathrm{n}}$ is much smaller than $t_{\mathrm{g}}$. The growth mechanism of the nucleus to a detectable size is predominant.

We have tested these different models, the best fit of experimental data was obtained assuming $t_{\mathrm{n}} \gg t_{\mathrm{g}}$. Only the model representing a good correlation of our experimental results is presented here. In our case, we assume that the formation time of a stable nucleus is much higher than the necessary time for the nucleus to grow to a detectable size $\left(t_{\mathrm{n}} \gg t_{\mathrm{g}}\right)$. So the induction time can be considered as inversely proportional to the nucleation rate and the induction time is expressed with only the first term of Eq. (3).

Combining Eqs. (1) and (4) for the mechanism of primary homogeneous nucleation and taking the logarithm of the induction time, we obtained

$\ln \left(t_{\text {ind }}\right)=\ln \left(\frac{N_{\mathrm{c}}}{K_{\mathrm{hom}}}+\frac{4}{27} \frac{\gamma_{\mathrm{s}}^{3} V_{\mathrm{m}}^{2} \beta^{3}}{k_{\mathrm{B}}^{3} \alpha^{2} v^{2} T^{3}} \frac{1}{\ln ^{2} S}\right.$

where $S$ is the supersaturation ratio calculated from the following equation:

$S=\frac{a_{ \pm}}{a_{ \pm}^{*}}=\frac{\gamma_{ \pm} C}{\gamma_{ \pm}^{*} C^{*}}$

The logarithm of activity coefficients has been estimated using the Brömley equation [10].

Eq. (4) suggests that for a given temperature, the plot of $\ln \left(t_{\text {ind }}\right)$ versus $\left(\ln ^{2} S\right)^{-1}$ should be a straight line. In the literature, it has been shown that the plots of $\ln \left(t_{\text {ind }}\right)$ versus $\left(\ln ^{2} S\right)^{-1}$ consist in two linear segments [11]. For high supersaturations (straightline (1)), the nucleation is predominantly homogeneous, and for low supersaturations (straightline (2)) the heterogeneous nucleation prevails (Fig. 1).

\subsection{Metastable zone widths}

This method consists in the determination of the maximum undercooling $\Delta T_{\max }$. A solution of known saturation temperature $T_{\text {sat }}$ is cooled to a temperature $T_{\text {lim }}$ at which 


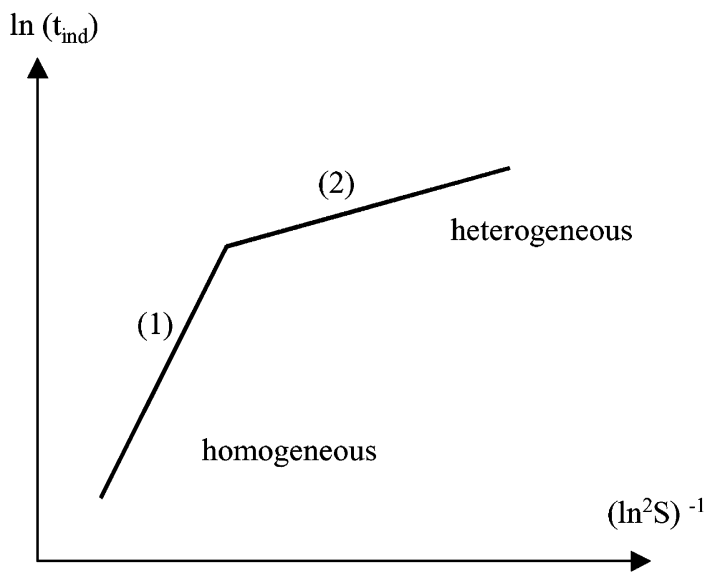

Fig. 1. Induction time as a function of initial supersaturation.

the birth of the first crystals is detectable. The maximum undercooling $\Delta T_{\max }$ is defined as the difference between the saturation temperature $T_{\text {sat }}$ and the temperature $T_{\mathrm{lim}}$. The maximum undercooling can be expressed in terms of the maximum supersaturation, $\Delta C_{\max }$ by the equation

$\Delta C_{\max }=\left(\frac{\mathrm{d} C^{*}}{\mathrm{~d} T} \quad \Delta T_{\max }\right.$

Nyvlt proposed a correlation between the mass of nuclei generated per unit mass of solution and the absolute supersaturation [12]

$J_{\mathrm{m}}=k_{\mathrm{n}} \Delta C_{\max }^{\mathrm{n}}$

The nucleation rate can be expressed in terms of the cooling rate $\dot{b}$

$J_{\mathrm{m}}=\left(\frac{\mathrm{d} C^{*}}{\mathrm{~d} T} \quad \dot{b}\right.$

Eqs. (6)-(8) yield

$\ln (\dot{b})=d_{1} \ln \left(\frac{\mathrm{d} C^{*}}{\mathrm{~d} T}+\ln \left(k_{\mathrm{n}}\right)+d_{2} \ln \left(\Delta T_{\max }\right)\right.$

where $\dot{b}$ is the cooling rate and $d_{1}$ and $d_{2}$ are constants. These constants depend on the apparent orders of nucleation or growth.

This is a very general relation. However, different assumptions on the physical mechanisms to be taken into account lead to different interpretations of constants $d_{1}$ and $d_{2}$. For instance, Nyvlt or Kubota assumed that only nucleation occurs before the crystals are detected: constants $d_{1}$ and $d_{2}$ are thus, simply related to the apparent order of nucleation, $n[12,13]$. For Söhnel and Nyvlt, constants $d_{1}$ and $d_{2}$ depend on the apparent orders of nucleation and growth [14]. If crystal growth is supposed to have a significant contribution, constants $d_{1}$ and $d_{2}$ are functions of the apparent order of growth, $g$ [15].

The determination of the nucleation rate constant $k_{\mathrm{n}}$ and the kinetic apparent order of nucleation rate $n$ and the linear

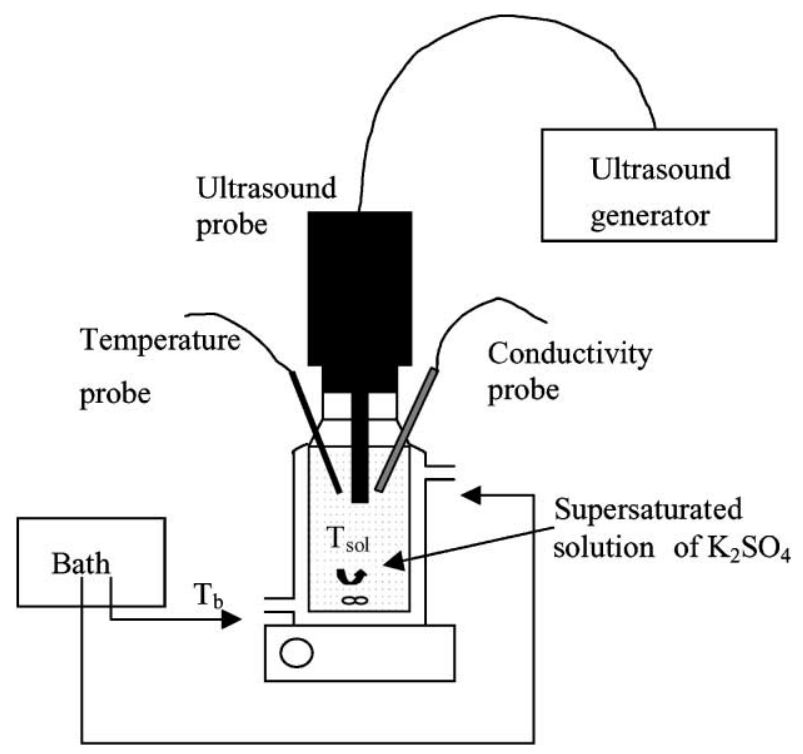

Fig. 2. Experimental apparatus.

growth rate order $g$ are derived from the plot of maximum undercooling $\Delta T_{\max }$ and cooling rate $\dot{b}$ on logarithmic coordinates.

\subsection{Ultrasound}

We used power ultrasound with a frequency equal to $20 \mathrm{kHz}$. When high energy pressure waves are applied to a liquid, cavitation bubbles made of vapour and dissolved gas are created. The cavitation consists in the formation, growth and implosion of these bubbles. The violent implosion of bubbles is called collapse and can induce very high local temperatures and pressures.

The dissipated power of ultrasound reported in the text has been estimated by calorimetry. These dissipated powers represent about $40 \%$ of the electrical power consumed by the generator.

\section{Experiments}

Aqueous solutions are prepared from potassium sulphate crystals (purity $>99 \%$ ) and distilled water. The experimental apparatus used for the determination of induction time and metastable zone widths is represented in Fig. 2. It consists of a thermostated reactor $(200 \mathrm{ml})$ stirred with a magnetic rod at a constant rotation speed of about $500 \mathrm{rpm}$. Ultrasound is applied at the top of the reactor by a stainless ultrasound transducer with a titanium tip. Two ultrasonic power levels have been used: 0.05 and $0.12 \mathrm{Wg}^{-1}$ solution. The conductivity and the solution temperature are respectively measured with instrumental resolutions $\pm 0.1 \mathrm{mS} \mathrm{cm}^{-1}$ and $\pm 0.01{ }^{\circ} \mathrm{C}$. We consider that the appearance of crystals is detected when there is a sudden decrease of the conductivity. 


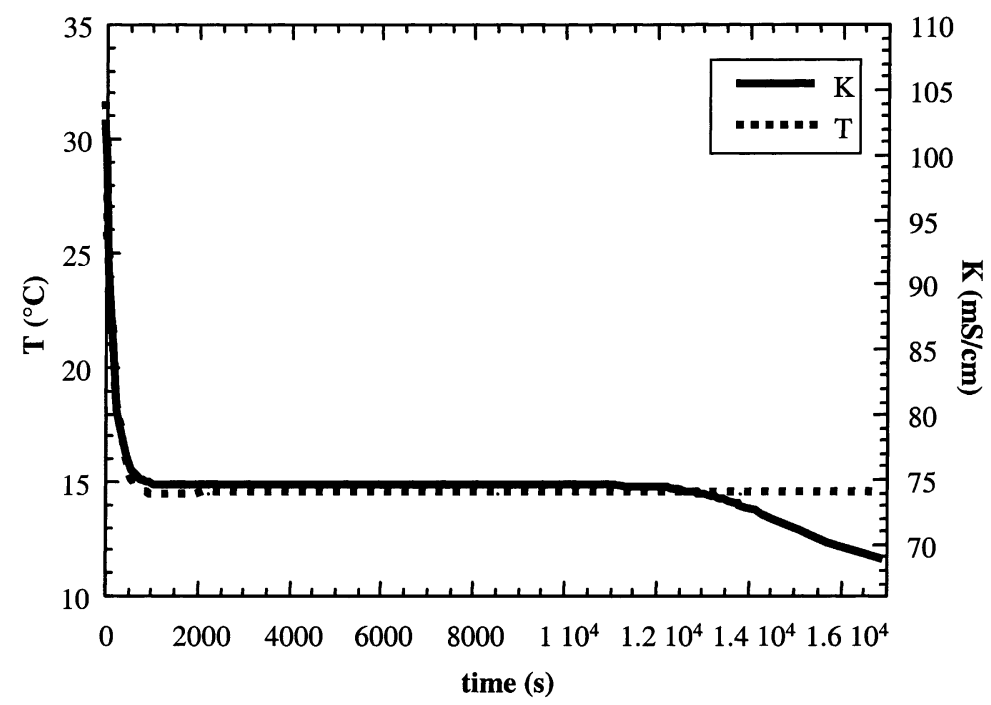

Fig. 3. Solution temperature and conductivity for an absolute supersaturation of $0.0156 \mathrm{~g} \mathrm{~K}_{2} \mathrm{SO}_{4} \mathrm{~g}^{-1}$ water.

Before each experiment, in order to dissolve all crystals, solutions are warmed to a temperature higher by 5 or $10^{\circ} \mathrm{C}$ than the saturation temperature $T_{\text {sat }}$ for $1 \mathrm{~h}$.

For all experiments, the saturation concentration of potassium sulphate in water solutions is calculated from the following equation [16]:

$C^{*}=6.7 \times 10^{-2}+2.3 \times 10^{-3} \times T-6.0 \times 10^{-6} \times T^{2}$

For induction time measurements, the initial saturation temperatures $\left(T_{\text {sat }}\right)$ ranged from 22 to $25^{\circ} \mathrm{C}$ for experiments without ultrasound, and from 19.5 to $23^{\circ} \mathrm{C}$ for experiments with ultrasound. The solutions are rapidly cooled to a temperature $T_{1}$ comprised between 14 and $16^{\circ} \mathrm{C}$. Ultrasound is applied at the end of the cooling phase. The induction time is measured as soon as the temperature $T_{1}$ is reached or when ultrasound is applied.

Measurements of metastable zone widths are carried out for a saturation temperature $\left(T_{\text {sat }}\right)$ equal to $30^{\circ} \mathrm{C}$. The cooling rates $\dot{b}$ of solutions range from 5 to $20^{\circ} \mathrm{Ch}^{-1}$. The solution is insonified at the beginning of the cooling phase.

\section{Results and discussion}

\subsection{Induction time}

The appearance of potassium sulphate crystals is detected by a drop in the conductivity of the solution. The time corresponding to the crystallisation corresponds to the time where

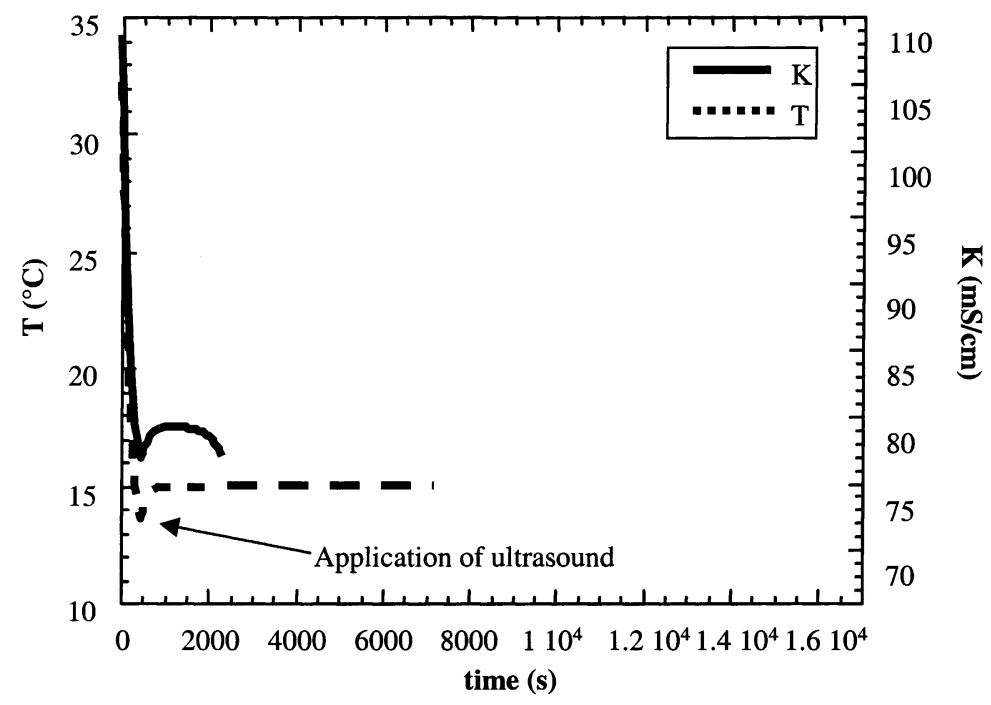

Fig. 4. Solution temperature and conductivity for an absolute supersaturation of $0.0156 \mathrm{~g} \mathrm{~K}_{2} \mathrm{SO}_{4} \mathrm{~g}^{-1}$ water and an ultrasound power equal to $0.05 \mathrm{~W} \mathrm{~g}^{-1}$ solution. 


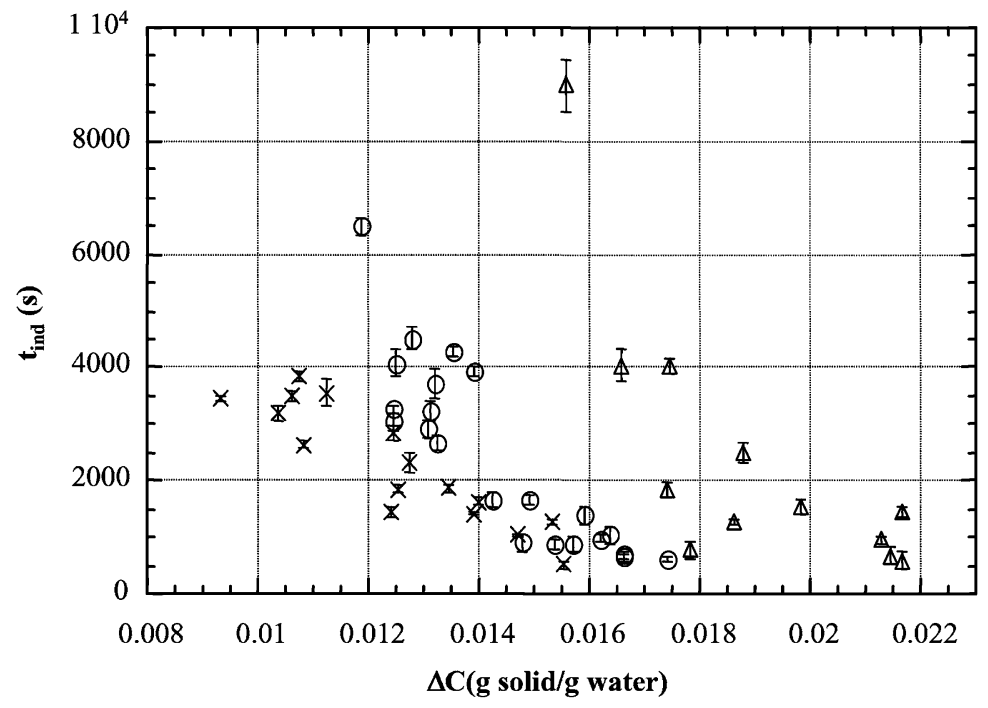

Fig. 5. Influence of ultrasound on the induction time of aqueous potassium sulphate solutions: $(\triangle)$ without ultrasound, $(\bigcirc) P_{\text {diss }}=0.05 \mathrm{~W} \mathrm{~g}{ }^{-1}$ solution, (×) $P_{\text {diss }}=0.12 \mathrm{~W} \mathrm{~g}^{-1}$ solution.

the derivative of the conductivity versus the time becomes negative.

Figs. 3 and 4 present the variation of the solution temperature and conductivity for an absolute supersaturation of $0.0156 \mathrm{~g} \mathrm{~K}_{2} \mathrm{SO}_{4} \mathrm{~g}^{-1}$ water. We can observe that the induction time without ultrasound is about $9000 \mathrm{~s}$ whereas with ultrasound it is about $1000 \mathrm{~s}$. Moreover, the conductivity decreases faster with ultrasound than without ultrasound. As the conductivity is proportional to the potassium sulphate concentration, this difference suggests that more crystalline surface is formed with ultrasound.

All results obtained for the variation of the induction time versus absolute supersaturation are presented in Fig. 5 and Table 1. The absolute supersaturation is calculated as the difference between the actual concentration and the saturation concentration. The maximum cooling time for experiments without ultrasound is about $900 \mathrm{~s}$ and for experiments with ultrasound it is about $450 \mathrm{~s}$. The mass error for the absolute supersaturation error is about $10^{-4} \mathrm{~g} \mathrm{~K}_{2} \mathrm{SO}_{4} \mathrm{~g}^{-1}$ water. The maximum error on the determination of the induction time is equal to $15 \%$ for experiments without ultrasound, to $11 \%$ for experiments at $0.05 \mathrm{~W} \mathrm{~g}^{-1}$ solution and to $12 \%$ for experiments and $0.12 \mathrm{~W} \mathrm{~g}^{-1}$ solution.

We obtained the same type of curve with and without ultrasound. The induction time decreases when absolute supersaturation increases. This behaviour agrees with classical results on crystallisation. However, we can observe that ultrasound has a significant effect on induction time,

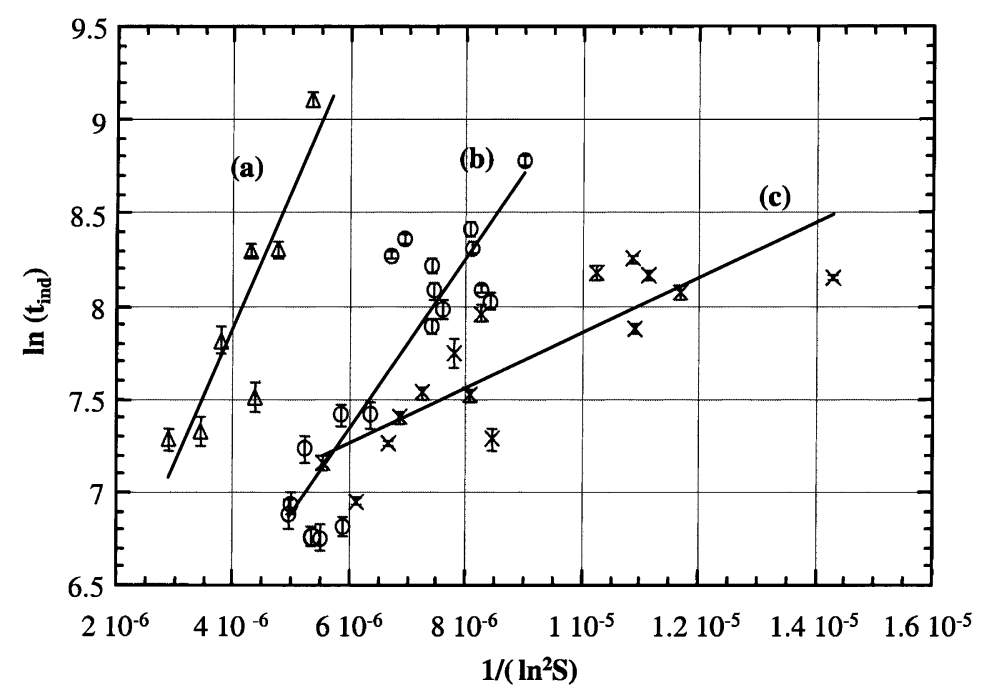

Fig. 6. Induction time as a function of final temperature and ratio supersaturation for potassium sulphate crystallisation: (a) without ultrasound, (b) $P_{\text {diss }}=0.043 \mathrm{~W} \mathrm{~g}^{-1}$ solution and (c), $P_{\text {diss }}=0.114 \mathrm{~W} \mathrm{~g}^{-1}$ solution. 
Table 1

Values of the induction time measurement

\begin{tabular}{|c|c|c|}
\hline$\Delta C\left(\mathrm{~g} \mathrm{~K}_{2} \mathrm{SO}_{4} \mathrm{~g}^{-1}\right.$ water $)$ & $t_{\text {ind }}(\mathrm{s})$ & Measure error $( \pm s)$ \\
\hline \multicolumn{3}{|l|}{ Without ultrasound } \\
\hline 0.0156 & 8978 & 340 \\
\hline 0.0166 & 4040 & 200 \\
\hline 0.0174 & 1830 & 140 \\
\hline 0.0175 & 4029 & 135 \\
\hline 0.0179 & 769 & 70 \\
\hline 0.0186 & 1276 & 45 \\
\hline 0.0188 & 2476 & 175 \\
\hline 0.0198 & 1520 & 120 \\
\hline 0.0213 & 959 & 65 \\
\hline 0.0215 & 672 & 100 \\
\hline 0.0217 & 591 & 70 \\
\hline 0.0217 & 1459 & 85 \\
\hline \multicolumn{3}{|l|}{$P_{\text {diss }}=0.05 \mathrm{~W} \mathrm{~g}^{-1}$ solution } \\
\hline 0.0119 & 6493 & 150 \\
\hline 0.0124 & 3053 & 150 \\
\hline 0.0125 & 3261 & 60 \\
\hline 0.0125 & 4080 & 125 \\
\hline 0.0128 & 4506 & 200 \\
\hline 0.0131 & 2915 & 150 \\
\hline 0.0131 & 3235 & 155 \\
\hline 0.0132 & 3715 & 150 \\
\hline 0.0132 & 2668 & 120 \\
\hline 0.0136 & 4275 & 100 \\
\hline 0.0139 & 3920 & 85 \\
\hline 0.0142 & 1658 & 120 \\
\hline 0.0148 & 910 & 50 \\
\hline 0.0149 & 1655 & 90 \\
\hline 0.0154 & 858 & 50 \\
\hline 0.0157 & 869 & 45 \\
\hline 0.0159 & 1382 & 100 \\
\hline 0.0162 & 975 & 75 \\
\hline 0.0164 & 1032 & 60 \\
\hline 0.0166 & 689 & 60 \\
\hline 0.0166 & 648 & 65 \\
\hline 0.0174 & 616 & 60 \\
\hline \multicolumn{3}{|l|}{$P_{\text {diss }}=0.12 \mathrm{~W} \mathrm{~g}^{-1}$ solution } \\
\hline 0.0093 & 3464 & 50 \\
\hline 0.0104 & 3204 & 135 \\
\hline 0.0106 & 3505 & 85 \\
\hline 0.0108 & 3837 & 80 \\
\hline 0.0108 & 2643 & 75 \\
\hline 0.0112 & 3560 & 150 \\
\hline 0.0124 & 1453 & 90 \\
\hline 0.0125 & 2857 & 135 \\
\hline 0.0125 & 1841 & 65 \\
\hline 0.0127 & 2308 & 175 \\
\hline 0.0135 & 1863 & 55 \\
\hline 0.0139 & 1421 & 25 \\
\hline 0.0140 & 1635 & 50 \\
\hline 0.0147 & 1044 & 20 \\
\hline 0.0153 & 1281 & 45 \\
\hline 0.0156 & 520 & 62 \\
\hline
\end{tabular}

especially at low absolute supersaturations $(<0.014 \mathrm{~g}$ $\mathrm{K}_{2} \mathrm{SO}_{4} \mathrm{~g}^{-1}$ water). This effect is less significant at high supersaturation when nucleation is very fast anyway.

In Fig. 6, the plots of $\ln \left(t_{\text {ind }}\right)$ versus $\left(\ln ^{2} S\right)^{-1}$ for experiments with and without ultrasound are represented. The values corresponding to an induction time lower than $1400 \mathrm{~s}$
Table 2

Calculation of the absolute supersaturation at the wall

\begin{tabular}{lll}
\hline$P_{\text {diss }}$ & $\Delta T=T_{\text {sol }}$ & $\Delta C_{\mathrm{W}}$ \\
$\left(\mathrm{W} \mathrm{g}^{-1}\right.$ solution $)$ & $-T_{\text {sol }}^{\mathrm{W}}\left({ }^{\circ} \mathrm{C}\right)$ & $\left(\mathrm{g} \mathrm{K}_{2} \mathrm{SO}_{4} \mathrm{~g}^{-1}\right.$ water $)$ \\
\hline 0.00 & 0.28 & $\Delta C+0.0006$ \\
0.05 & 0.89 & $\Delta C+0.0019$ \\
0.12 & 1.23 & $\Delta C+0.0026$ \\
\hline
\end{tabular}

for experiments without ultrasound and lower than $700 \mathrm{~s}$ for experiments with ultrasound are not taken into account because the cooling time is too high in comparison with the induction period. The corresponding equations are

$$
\begin{aligned}
P_{\text {diss }}= & 0.00 \mathrm{~W} \mathrm{~g}^{-1} \text { solution, } \\
\ln \left(t_{\text {ind }}\right)= & \left(3.69 \times 10^{-2} \pm 0.06 \times 10^{-2}\right)\left(\ln ^{2} S\right)^{-1} \\
& +(4.85 \pm 0.11) \\
P_{\text {diss }}= & 0.05 \mathrm{~W} \mathrm{~g}^{-1} \text { solution, } \\
\ln \left(t_{\text {ind }}\right)= & \left(2.35 \times 10^{-2} \pm 0.05 \times 10^{-2}\right)\left(\ln ^{2} S\right)^{-1} \\
& +(4.42 \pm 0.12) \\
P_{\text {diss }}= & 0.12 \mathrm{~W} \mathrm{~g}^{-1} \text { solution, } \\
\ln \left(t_{\text {ind }}\right)= & \left(0.91 \times 10^{-2} \pm 0.02 \times 10^{-2}\right)\left(\ln ^{2} S\right)^{-1} \\
& +(6.12 \pm 0.06)
\end{aligned}
$$

The numerical values of the slopes are low, suggesting that the main mechanism is heterogeneous primary nucleation [11]. When ultrasound is applied or when ultrasound power increases, the slope decreases. This change of slope suggests that ultrasound modifies the product $\left[\gamma_{\mathrm{s}}^{3} f(\theta)\right]$ (Eq. (1)) [17]. Ultrasound seems to change the activation energy to act on either the surface energy crystal-solution or the contact angle. So, ultrasound may decrease the critical radius.

For experiments at $0.12 \mathrm{~W} \mathrm{~g}^{-1}$ solution, there seems (Fig. 6) to be a break for $\left(1 / \mathrm{ln}^{2} S\right)$ contained between 160 and 200. This change corresponds to the low values of the induction time. This break could correspond to a change in the nucleation mechanism.

However, when ultrasound is applied to the solution, a lower wall temperature is required to maintain the same reactor temperature in order to allow the ultrasound power to be removed by the jacket. Therefore, the absolute supersaturation at the wall is higher when ultrasound is applied, and this could result in a shortening of the induction time. In order to distinguish between the specific contributions of ultrasound and of this thermal effect, we have estimated the wall temperature as a function of the solution temperature and ultrasound power (see Appendix A). We can then calculate the absolute supersaturation at the wall $\Delta C_{\mathrm{w}}$, as a function of the bulk absolute supersaturation $\Delta C$, for experiments with and without ultrasound (see Table 2). The difference between both supersaturations (bulk and wall) is negligible in experiments without ultrasound, but increases 


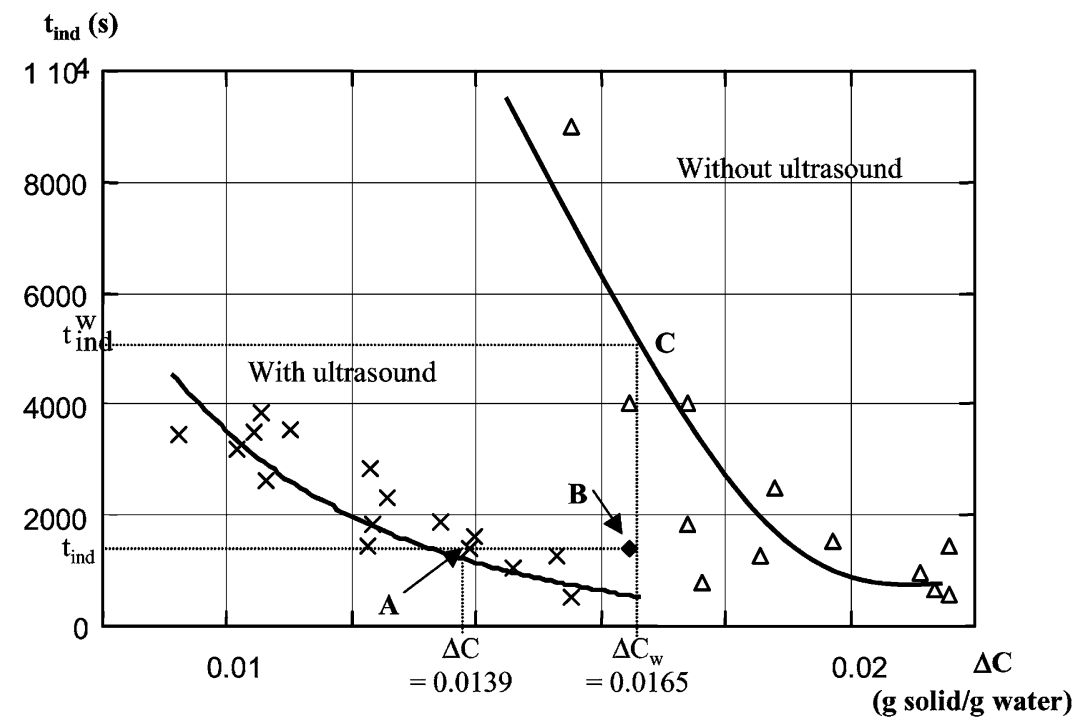

Fig. 7. Induction time as a function of supersaturation with and without for an ultrasound power of $0.114 \mathrm{~W} \mathrm{~g} \mathrm{~g}^{-1}$ solution.

significantly with ultrasound power: one might suspect that the observed effect of ultrasound could be simply due to this artefact.

For experiments with ultrasound, it can be verified that the measured induction time is always much shorter than the induction time, which would have been observed without ultrasound with a supersaturation equal to $\Delta C_{\mathrm{w}}$ (Fig. 7). For a bulk supersaturation $\Delta C$ (point $\mathrm{A}$ ), the corresponding wall supersaturation is $\Delta C_{\mathrm{w}}$ (point $\mathrm{B}$ ). For this supersaturation, the induction time without ultrasound $t_{\text {ind }}^{\mathrm{W}}$ (about $5800 \mathrm{~s}$, point $C$ ) remains much higher than the measured one (1421 s, point B).

As a result, we can conclude that ultrasound has a strong specific effect on nucleation, which can by no means be explained by the wall temperature effect.

\subsection{Metastable zone widths}

The measurements of the metastable zone width with and without ultrasound are presented in Fig. 8 and in Table 3. Correlation equations of the data are

(a) Without ultrasound

$$
\ln (\dot{b})=(5.81 \pm 0.30) \ln \left(\Delta T_{\max }\right)-(11.69 \pm 0.91)
$$

(b) With ultrasound

$$
\ln (\dot{b})=(2.74 \pm 0.18) \ln \left(\Delta T_{\max }\right)-(3.55 \pm 0.52)
$$

(c) Nyvlt et al. $\ln (\dot{b})=13.64 \ln \left(\Delta T_{\max }\right)-31.24$

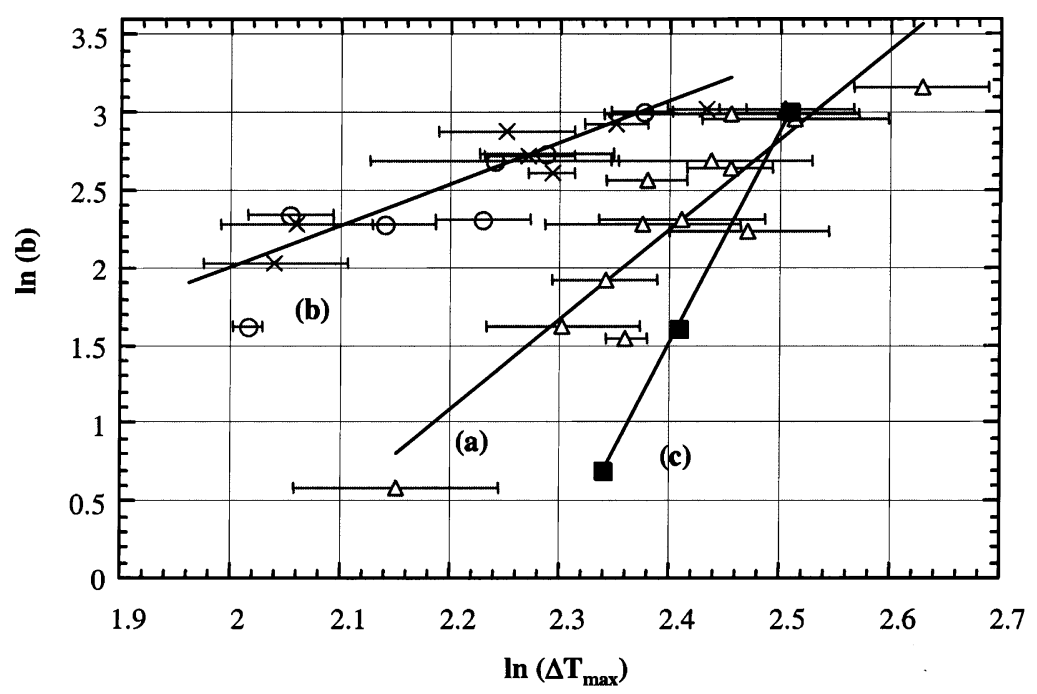

Fig. 8. Nucleation characteristics of potassium sulphate aqueous solutions which saturation temperature is $30^{\circ} \mathrm{C}$ : (a) without ultrasound, (b) with ultrasound and (c) Nyvlt et al. 
Table 3

Average values of the measurement of the metastable zone width for a saturation temperature equal to $30^{\circ} \mathrm{C}$

\begin{tabular}{|c|c|c|c|}
\hline$\dot{b}\left({ }^{\circ} \mathrm{Ch}^{-1}\right)$ & $\Delta T_{\max }\left({ }^{\circ} \mathrm{C}\right)$ & $\begin{array}{l}\text { Total error } \\
\left( \pm^{\circ} \mathrm{C}\right)\end{array}$ & $\begin{array}{l}\text { Experiments } \\
\text { number }\end{array}$ \\
\hline \multicolumn{4}{|c|}{ Without ultrasound } \\
\hline 1.80 & 8.6 & 0.80 & 1 \\
\hline 4.68 & 10.60 & 0.20 & 1 \\
\hline 5.04 & 10.00 & 0.70 & 4 \\
\hline 6.84 & 10.40 & 0.50 & 1 \\
\hline 9.36 & 11.85 & 0.85 & 2 \\
\hline 9.72 & 10.76 & 0.96 & 5 \\
\hline 10.08 & 11.15 & 0.85 & 2 \\
\hline 12.96 & 10.80 & 0.40 & 1 \\
\hline 14.04 & 11.65 & 0.45 & 2 \\
\hline 14.76 & 11.45 & 1.05 & 4 \\
\hline 19.08 & 12.35 & 1.05 & 2 \\
\hline 19.80 & 11.65 & 1.35 & 2 \\
\hline 20.52 & 12.25 & 0.75 & 2 \\
\hline 22.05 & 13.85 & 0.85 & 2 \\
\hline \multicolumn{4}{|c|}{$P_{\text {diss }}=0.05 \mathrm{~W} \mathrm{~g} \mathrm{~g}^{-1}$ solution } \\
\hline 5.04 & 7.50 & 0.10 & 1 \\
\hline 10.44 & 7.80 & 0.30 & 1 \\
\hline 9.72 & 8.50 & 0.20 & 2 \\
\hline 10.08 & 9.30 & 0.40 & 1 \\
\hline 14.76 & 9.40 & 1.10 & 2 \\
\hline 15.48 & 9.85 & 0.60 & 1 \\
\hline 20.16 & 10.75 & 0.30 & 1 \\
\hline \multicolumn{4}{|c|}{$P_{\text {diss }}=0.12 \mathrm{~W} \mathrm{~g}^{-1}$ solution } \\
\hline 7.56 & 7.70 & 0.50 & 1 \\
\hline 9.72 & 7.85 & 0.55 & 2 \\
\hline 13.68 & 9.90 & 0.20 & 1 \\
\hline 15.12 & 9.70 & 0.40 & 1 \\
\hline 17.64 & 9.50 & 0.60 & 1 \\
\hline 18.72 & 10.50 & 0.30 & 1 \\
\hline 20.52 & 11.40 & 0.40 & 1 \\
\hline
\end{tabular}

We can consider that our results obtained without ultrasound (a) are comparable with those of Nyvlt et al. (c) $[15,18]$ with respect to the difficult control of the primary nucleation. This behaviour is strongly modified when ultrasound is applied; but we did not observe a significant difference between the two tested ultrasonic powers $\left(0.05\right.$ and $0.12 \mathrm{~W} \mathrm{~g}^{-1}$ solution $)$. The slope of the $\ln (\dot{b})$ versus $\ln \left(\Delta T_{\max }\right)$ line is strongly reduced with ultrasound, while the intercept point is increased. From Eq. (10) we can conclude that ultrasound decreases the apparent order of nucleation $n$.

As for the determination of the absolute supersaturation at the wall, we can estimate the metastable zone width at the wall. For these measurements, the difference between the solution temperature and the inner wall temperature is not significant. The difference is about $0.16^{\circ} \mathrm{C}$ without ultrasound and about $0.55^{\circ} \mathrm{C}$ with ultrasound. The maximum undercooling at the wall $\Delta T_{\max }^{\mathrm{w}}$ with ultrasound is always lower than the maximum undercooling at the wall $\Delta T_{\max }^{\mathrm{W}}$ and in the solution $\Delta T_{\max }$ without ultrasound. Thus, we observe only an effect of the ultrasound on the metastable zone width.

\section{Conclusions}

It has been shown that ultrasound can influence the primary nucleation of potassium sulphate.

Ultrasound reduces the induction time especially for low absolute supersaturation. For experiments with ultrasound, the predominant effect has been identified as a specific effect of ultrasound and not an effect of the lower wall temperature. The exploitation of the induction time models shows that the main mechanism is a heterogeneous primary nucleation mechanism. Using the different models of classical primary nucleation theory, ultrasound seems to decrease the activation energy so they can decrease the critical radius. However, these different models do not allow an explanation of the mechanism of the action of ultrasound.

The metastable zone width can also be reduced by the application of ultrasound. The apparent orders of nucleation or growth are decreased by ultrasound. Results indicate that it would be sufficient to apply a low ultrasonic power to decrease the metastable zone width. Hence, ultrasound decreases the apparent order of the primary nucleation rate and increases the rate of appearance of the solid.

It seems that ultrasound modified the mechanism of nucleation itself, since the apparent order of nucleation is strongly reduced in the presence of ultrasound.

Some explanations can be proposed on the action of ultrasound:

- Does ultrasound increase the heterogeneity of the system or does it create new nucleation sites?

- The increase of the nucleation rate could be explained by the presence of shock waves in the solution. These waves could increase the probability of collisions of a molecule and a molecular aggregate.

With this study, we have shown that ultrasound permits to set off nucleation at supersaturations lower than without ultrasound. In industrial crystallisation processes, ultrasound can induce nucleation in conditions where spontaneous primary nucleation cannot occur without ultrasound. Moreover, ultrasound could allow seeding to be avoided and thus avoiding the introduction of foreign particles into the solution.

\section{Appendix A}

From classical relations of thermal transfer in a reactor we have calculated the difference $\square T$, between the solution temperature $\left(T_{\mathrm{sol}}\right)$ and the wall temperature $\left(T_{\mathrm{sol}}^{\mathrm{w}}\right)($ Fig. 9).

The transfer heat flux is expressed as

$$
\begin{aligned}
& \phi=U \bar{S}\left(T_{\mathrm{sol}}-T_{\mathrm{f}}\right) \\
& \phi=h_{\mathrm{s}} S_{\mathrm{int}}\left(T_{\mathrm{sol}}-T_{\mathrm{sol}}^{\mathrm{w}}\right)
\end{aligned}
$$

The overall heat transfer coefficient expression is given as

$\frac{1}{U \bar{S}}=\frac{1}{h_{\mathrm{s}} S_{\mathrm{int}}}+\frac{1}{h_{\mathrm{f}} S_{\mathrm{ext}}}+\frac{e}{\lambda_{p} \bar{S}}$ 


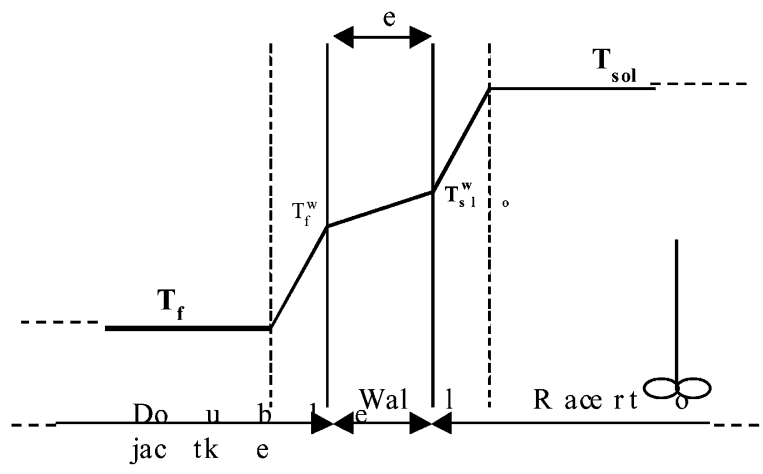

Fig. 9. Thermal transfer through an exchange wall during a cooling.

where $\bar{S}, S_{\text {int }}$ and $S_{\text {ext }}$ are respectively the mean exchange surface, the inner exchange surface and the outer exchange surface.

Replacing the inner heat transfer, the overall heat transfer can be connected with the stirrer rate $N$ by the following equation:

$\frac{1}{U \bar{S}}=s \times N^{(-a)}+\frac{1}{h^{\prime} S^{\prime}}$

where

$\frac{1}{h^{\prime} S^{\prime}}=\frac{1}{h_{\mathrm{f}} S_{\mathrm{ext}}}+\frac{e}{\lambda_{p} \bar{S}}$

Knowing $e, \lambda_{p}$ and the different surfaces, the heat transfer coefficient between the wall and the cooling fluid, $h_{\mathrm{f}}$ can be calculated from the intercept of Eq. (A.4) (i.e. $N_{\mathrm{c}}$ tends to infinity) from experimental overall heat transfer data against $N$.

Then, with the Eq. (A.3) we can determine the heat transfer coefficient between the wall and the solution, $h_{\mathrm{s}}$ and calculate the wall temperature (Eqs. (A.1) and (A.2)).

\section{References}

[1] V.V. Yaminskii, K.B. Yaminskaya, A.V. Pertsov, Effect of ultrasound on nucleation and coagulation in crystallisation from solution, Coll. J. USSR 53 (1991) 83-86.

[2] P.D. Martin, E.J. Phillips, C.J. Price, Power ultrasound-a new tool for controlling crystallisation, in: Proceedings of the IChemE Symposium on Environment Research, Birmingham, 1993, pp. 516-518.

[3] R. Srinivasan, I.Z. Shirgaonkar, A.B. Pandit, Effect of sonication on crystal properties, Sep. Sci. Technol. 30 (10) (1995) 2239-2243.

[4] J.W. Mullin, C. Gaska, Potassium sulphate crystal growth rate in aqueous solution, J. Chem. Eng. Data 18 (1973) 217-308.

[5] J. Nyvlt, O. Söhnel, M. Matuchova, M. Broul, The Kinetics of Industrial Crystallisation, Elsevier, Amsterdam, 1985.

[6] A.G. Jones, J.W. Mullin, Crystallisation kinetics of potassium sulphate in a draft-tube agitated vessel, Trans. INSTN Chem. ENGRS 51 (1973) 302-308.

[7] W.J. Dunning, General and theoretical introduction, in: A.C. Zettlemoyer (Ed.), Nucleation, Marcel Dekker, New York, 1969, pp. 1-67.

[8] J.W. Mullin, Crystallisation, 2nd Edition, Butterworth-Heinemann Ltd., London, 1972, p. 573.

[9] D. Kashchiev, D. Verdoes, A.G. Van Vermolen, Induction time and metastability limit in new phase formation, J. Crystal Growth 110 (1991) 373-380.

[10] A. Mersmann, Crystallisation Technology Handbook, 1995.

[11] O. Söhnel, J.W. Mullin, Interpretation of crystallisation induction periods, J. Coll. Interf. Sci. 123 (1) (1988) 43-50.

[12] J. Nyvlt, Kinetics of nucleation in solutions, J. Crystal Growth 3 (4) (1968) 377-383

[13] N. Kubota, H. Karasawa, T. Kawakami, On estimation of critical supercooling from waiting times measured at constant supercooling, J. Chem. Eng. Jpn. 11 (4) (1978) 290-295.

[14] O. Söhnel, J. Nyvlt, Evaluation of experimental data on width of metastable region in aqueous solution, Collection Czech. Chem. Commun. 40 (1975) 511-518.

[15] A.H. Janse, E.J. De Jong, On the width of the metastable zone, Trans. IChemE 56 (1978) 187-193.

[16] J.W. Mullin, C. Gaska, Potassium sulphate crystal growth rate in aqueous solution, J. Chem. Eng. Data 18 (2) (1963) 217-220.

[17] Q. Tai-Quin, Nucleation of succrose solution by sound field, Int. Sugar J. 95 (1140) (1993) 513-519.

[18] J. Nyvlt, R. Rychly, J. Gottfried, J. Wurzelova, Metastable zone width of some aqueous solutions, J. Crystal Growth 6 (1970) 151-162. 